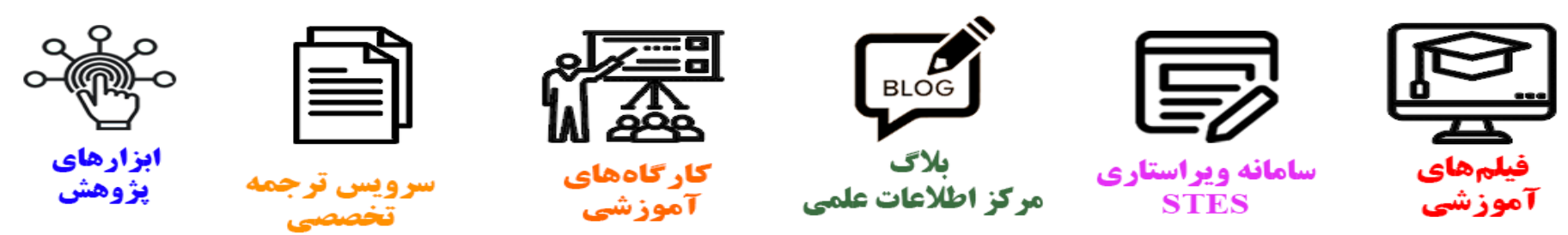

\title{
(c)
}

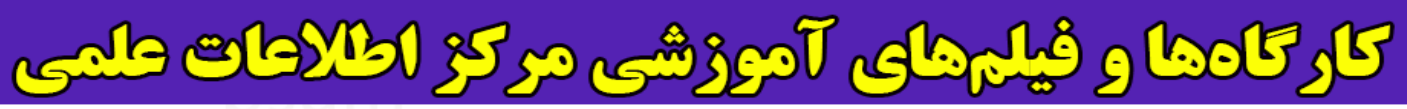
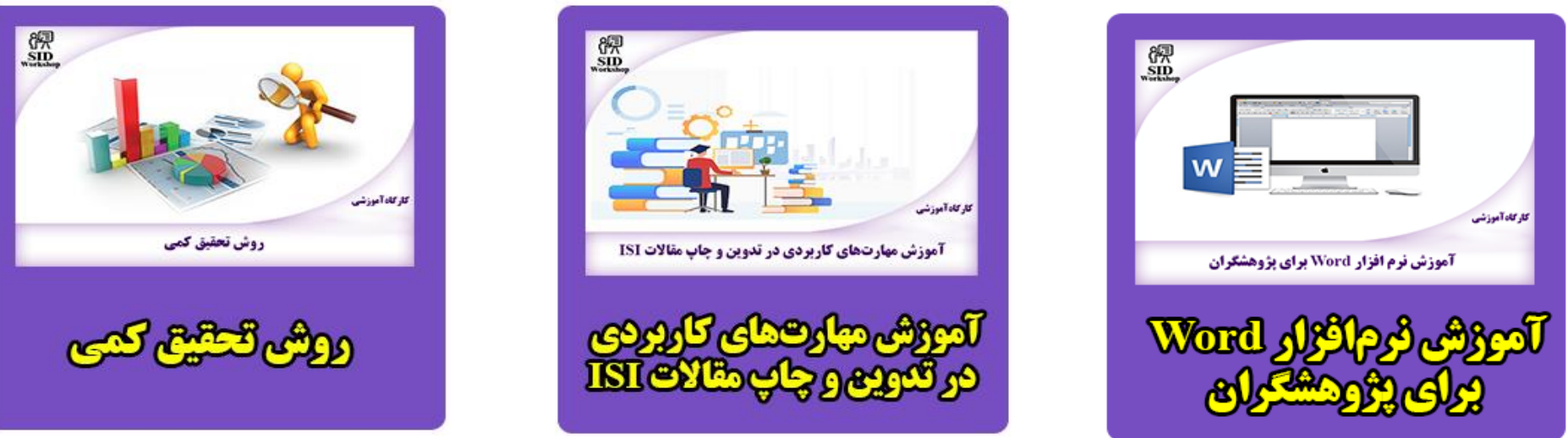
Int.J.Nano Dim. 2(1): 25-28, Summer 2011

ISSN: 2008-8868

Contents list available at IJND

International Journal of Nano Dimension

Journal homepage: $w w w . I J N D . i r$

\section{The use of magnetite nanoparticles in applied medicine}

\section{A. N. Belousov* \\ Laboratory of Applied Nanothechnology, pr. Lenina, 31- v, fl. 32, Kharkov, 61072, Ukraine.}

Received: 10 May 2011

Accepted: 07 July 2011
* Corresponding author:

Andrey N. Belousov

Laboratory of Applied

Nanothechnology, pr. Lenina, 31-

v, fl. 32, Kharkov, 61072, Ukraine.

Tel +3(8050)915-18-89

Fax +3(8050)915-18-89

Emailanb@vlink.kharkov.ua an.belousov2012@yandex.ua

\section{ABSTRACT}

Nowadays nanotechnology as a new direction of science allows us to develop therapeutic methods of the endogenous intoxication syndrome and to create a new class of biocompatible sorbents. In Ukraine first preparations of medical nanotechnology were produced and patented in 1998. These are IKBB (intracorporeal biocorrector), magnetcontrolled sorbent (MCS-B), and Micromage-B. The preparations are based on colloid magnetite particles $\left(\mathrm{Fe}_{3} \mathrm{O}_{4}\right)$ from 6 to $12 \mathrm{~nm}$. Adsorption layer provides a high sorption activity to magnetite nanoparticles. Total activity of their sorption surface is $800-1200 \mathrm{~m} 2 / \mathrm{g}$, magnetic field intensity produced by each particle is $300-400 \mathrm{kA} / \mathrm{m}, \zeta$ - potential is $19 \mathrm{mV}$. Each magnetite particle is a subdomain elementary magnetite of a sphere shape. The main biological action of nanotechnology preparations is directed towards regulation of cell metabolism. Therapeutic effect of this preparation is based on the influence of adsorption process and of constant magnetic field that surrounds colloid magnetite particle on cellular and subcellular structures. Point of attack is surface proteins of cell membranes. Colloid magnetite particles modify composition of protein molecules thereby affecting the transport of substances to a cell. Using magnet-controlled sorbent the method of extracorporal hemocorrection on the whole is more effective and reliable way to activate natural processes of detoxication of organism, than that of artificial detoxication. The absence of contra-indication and incidental effects (haematic, haemodynamic, hormone, electrolytic, immune) creates real predisposition for using this method in intensive therapy of intoxication syndrome.

Keywords: Magnetite nanoparticles; Medical nanotechnology; Regulation of cell metabolism; Intensive therapy; Intoxication syndrome

\section{INTRODUCTION}

In Ukraine, first preparations of medical nanotechnology were produced and patented in 1998. These are IKBB (intracorporal biocorrector), magnet-controlled sorbent brand of MCS-B, and Micromage- $\mathrm{B}[1,2]$. The preparations are based on colloid magnetite particles $\left(\mathrm{Fe}_{3} \mathrm{O}_{4}\right)$ from 6 to $12 \mathrm{~nm}$. 
Adsorption layer provides a high sorption activity to magnetite nanoparticles. Total activity of their sorption surface is $800-1200 \mathrm{~m} 2 / \mathrm{g}$, magnetic field intensity produced by each particle is 300 $400 \mathrm{kA} / \mathrm{m}$ and $\zeta$ - potential is $-19 \mathrm{mV}$.

Extracorporal hemocorrection method with the application of magnet-controlled sorbent (MCSB) has a significant pathogenetic advantage over the existing detoxication methods [3].

\section{EXPERIMENTAL}

Was established sorption activity of magnetite nanoparticles regarding heavy metal salts, nitrates, phenol, and passivity of the main electrolytes of blood plasma $\left(\mathrm{Ca}^{++}, \mathrm{Na}^{+}, \mathrm{Cl}^{-}, \mathrm{K}^{+}\right.$, $\left.\mathrm{Mg}^{++}\right)$. This allows using magnet-controlled sorbent MCS-B for cleaning biological body liquids without a threat of electrolytic disorder.

\section{RESULTS AND DISCUSSION}

It is also important to mention that magnet-controlled sorbent has not only a sorption effect but also an indirect effect caused by the influence of a constant magnetic field created by magnetite nanoparticles.

An important advantage of magnetcontrolled sorbent MCS-B is that its sorption qualities are highly specific (selective) and also they have a big resemblance with molecular components of blood plasma which stimulate endogenous intoxication syndrome.

Such a selectivity of magnet-controlled sorbent creates prerequisites for indirect sanogenetic effects in the process of therapy. A particular characteristic of the extracorporal hemocorrection method with application of magnet-controlled sorbent is activation the processes of the systemic nonspecific biological modulation. The presence of a constant magnetic field around magnetite nanoparticles allows magnet-controlled sorbent to not only perform a selective adsorption of various substances as in magnetic phoresis, but also to actively affect intracellular biochemical processes. Activating the process of oxyhemoglobin dissociation up to 1.5-2 times and raising output of blood oxygen to tissues, magnet-controlled sorbent restores bioelectric potential of erythrocyte membranes, improves operation of blood cells, normalizes rheology and microcirculation (Figure 1,2).

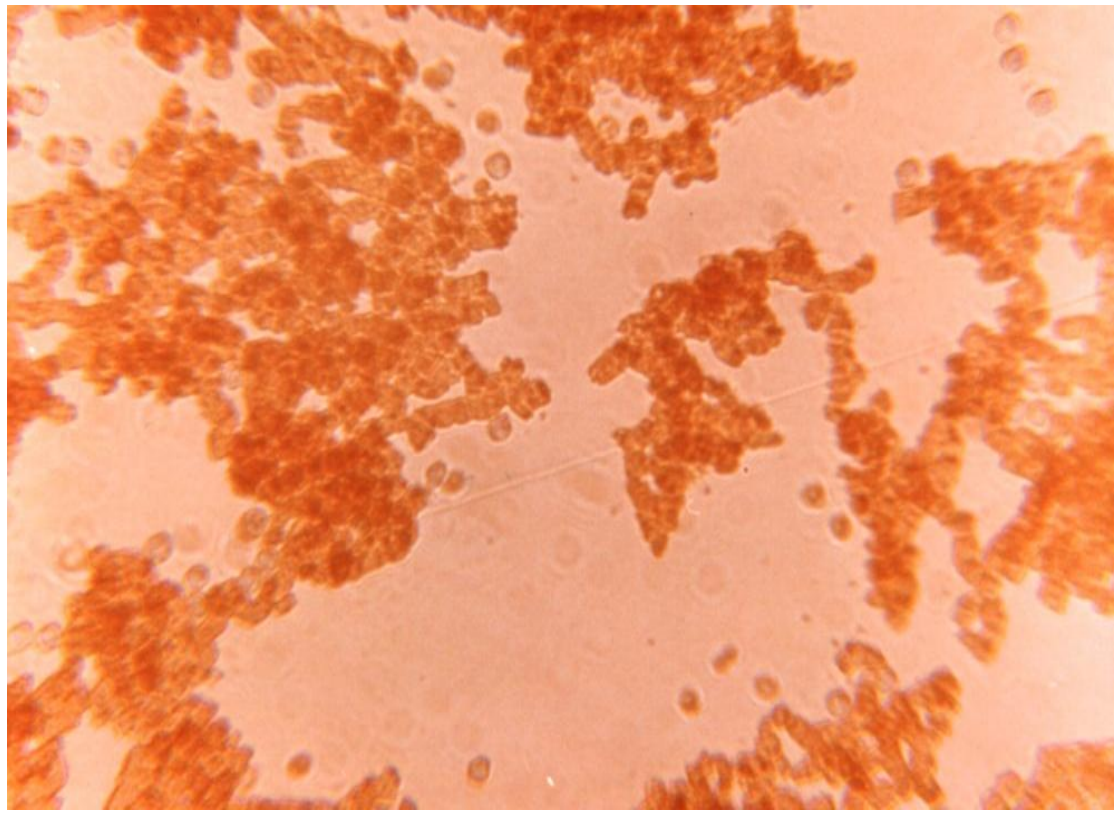

Fig.1. Initial state of erythrocytes (marked sludge syndrome) of heparinized blood of a patient with K. with toxemia (x 200). 


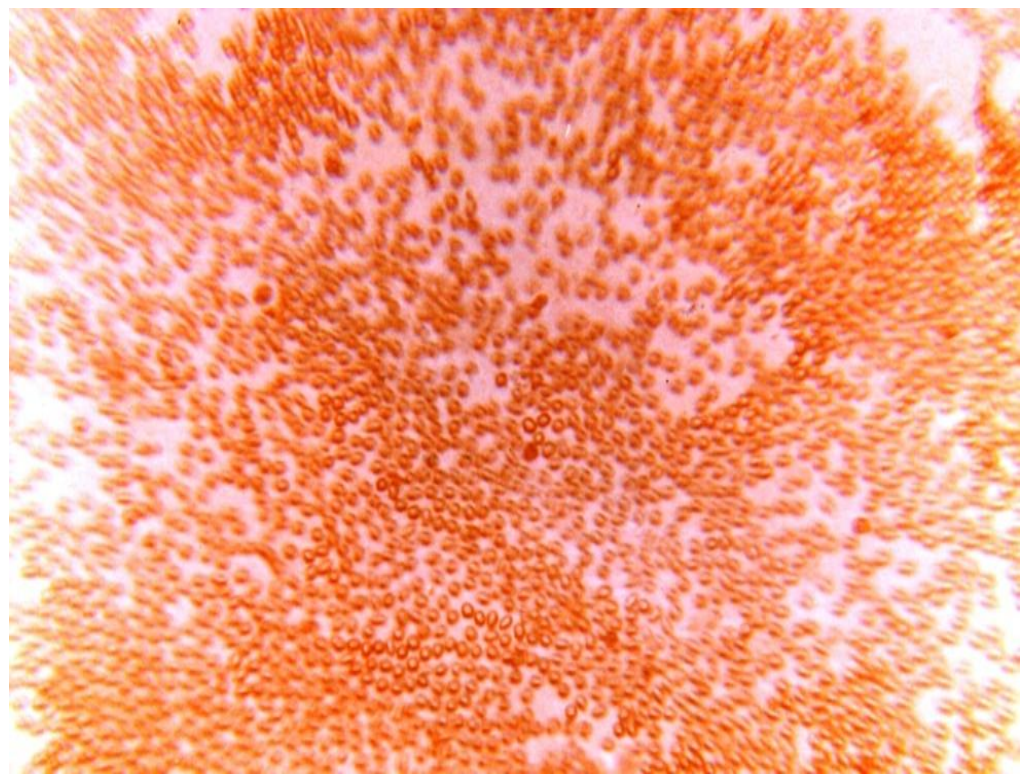

Fig.2. State of erythrocytes (elimination of sludge syndrome) of heparinized blood of a patient with K. with toxemia after the treatment with magnetite nanoparticles in vitro (x 200).

The mechanism corrects of $\mathrm{pH}$ and alkaline reserve of venous blood connected with changes in hemoglobin buffer system by magnetcontrolled sorbent nanoparticles. Improvement of metabolic disorders at cell level has been confirmed by the results of electron microscope examination of the organs of reticuloendothelial system (liver, kidneys, and lungs) in experiment.

Restoration of metabolic shifts of homeostasis, balance between antiradical and proradical products characterizes a direct effect of magnet-controlled sorbent on free radical oxidation of lipids. This fact predetermines the main pathogenetic difference of the offered method from the other types of intensive therapy. Correction of balance between antiradical and proradical products provides an activity of magnet-controlled sorbent regarding pathogenic germs and condition of cellular immunity. As a result, sensitivity of pathogenic germs (Staphylococcus aureus, Pseudomonas aeruginosa, Corynebacterium diphtheria, fungi of Candida type) to antibiotics increases in 2-3 times. Also was established pronounced bacteriostatic effect regarding pathogenic microflora.

At the same time, MCS-B nanoparticles do not cause changes of biological characteristics of normal flora with exception of short term slight inhibition of growth qualities.
Selective bacteriostatic and antifungal effects, correction of immunologic disorder (increase in phagocytic activity of leucocytes and in phagocytosis completeness index, liquidation of immunoregulatory cells disbalance) complete the list of biological effects of magnet-controlled sorbent nanoparticles.

The principle of magnetic phoresis allows magnet-controlled sorbent nanoparticles to restore indices of protein (Figure 3) and lipid blood fractions that allow improving albumin-globulin coefficient and index of ESR (erythrocytes sedimentation rate).

\section{CONCLUSION}

The proposed method of using MCS-B nanoparticles is technically simple and reliable in action. Absence of side effects (haemic, hemodynamic, electrolytic, hormonal, protein, lipid, immunological) creates real prerequisites for using this method in intensive therapy of patients with clinical cases of endogenous intoxication syndrome. This method can be used in cases when the other methods of artificial detoxication are contraindicated (anaemia, hypoproteinemia, coagulopathy, thrombocytopenia) [4]. 


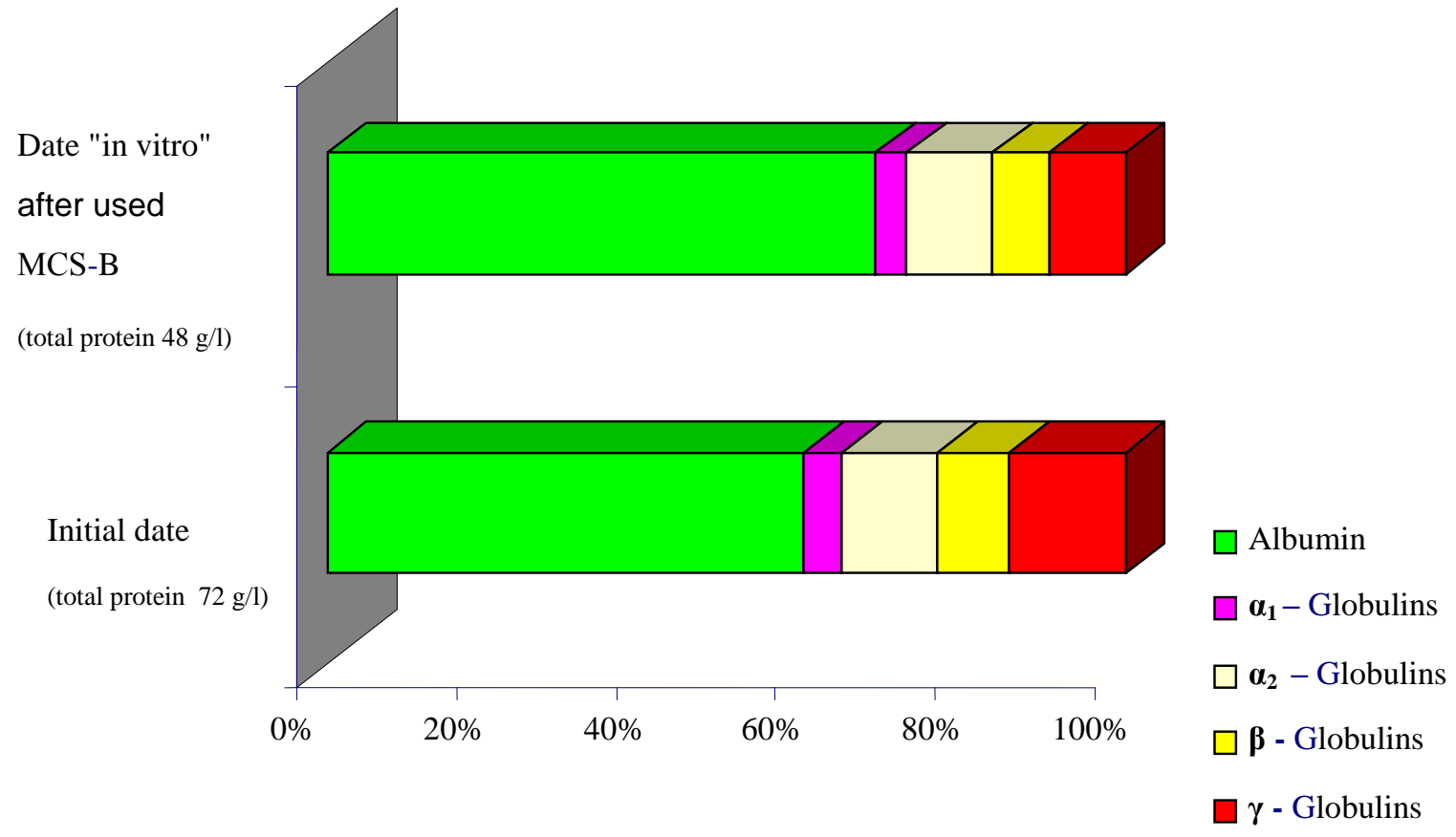

Fig. 3. Effect selective sorption protein fraction of blood by magnetite nanopaticles.

\section{REFERENCES}

[1] Belousov A.N., (2000), The treatmentprophylactic a product Micromage-B: the State patent №30538A UA A 23L 1/304 (Ukraine). Bull. № 6-11. - 3 p.

[2] Belousov A.N., (1998), The sorbent for extracorporal detoxycation of biological liquids: The State patent №24322A UA A61N2/00 (Ukraine). Bull. №7. - 4 p.

[3] Belousov A.N., (1998). The method extracorporal detoxycation of biological liquids: The State patent №24183A UA A61N2/00 (Ukraine). Bull. №7. - 3 p.

[4] Belousov A.N., (2004), The extracorporal hemocorrection with application of magnetcontrolled sorbent in intensive therapy of syndrome intoxication in the patients with a pathology hepatopancreatoduodenum zones: The abstract dissertation of doctor medicine: 14.01.30. / Dnepropetrovsk state of medical academy. $-40 \mathrm{p}$. 


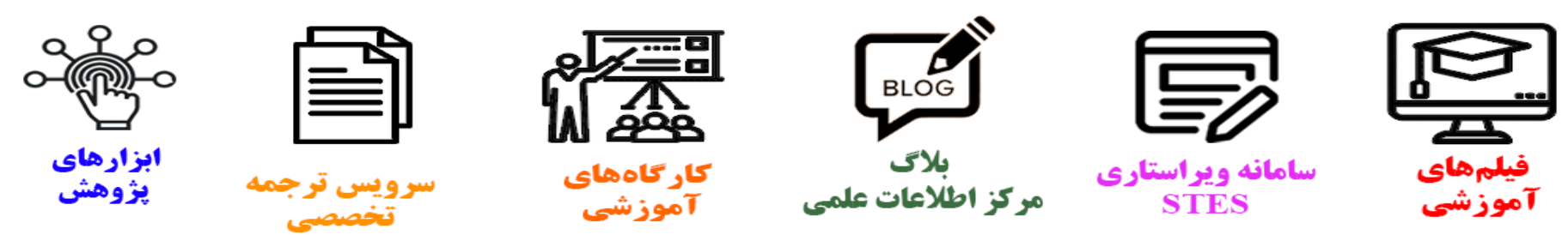

\section{(c)}

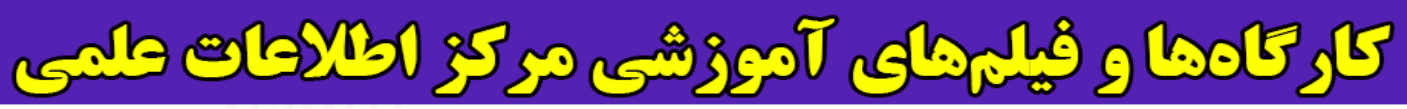
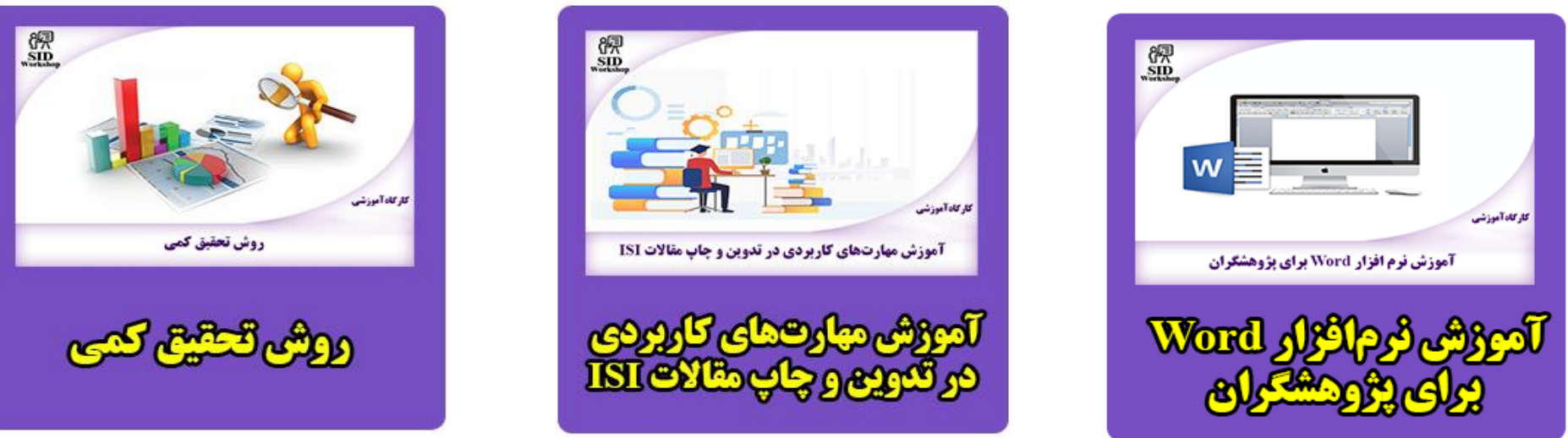